\title{
The Non-ossifying Fibroma: A Case Report and Review of the Literature
}

\author{
Leah M. Bowers • Donald M. Cohen • \\ Indraneel Bhattacharyya $\cdot$ James C. Pettigrew Jr. \\ Mary F. Stavropoulos
}

Received: 7 July 2012/ Accepted: 13 September 2012/Published online: 25 September 2012

(C) Springer Science+Business Media New York 2012

\begin{abstract}
The non-ossifying fibroma (NOF) is a benign, non-neoplastic lesion most commonly seen in the metaphyses of the long bones in children. While rare, the NOF has been reported in the mandible. The NOF in the extra-gnathic skeleton has a characteristic radiographic appearance, is typically asymptomatic and has a variable histologic make-up. Correlation of the radiographic appearance, clinical presentation and histopathology allows for differentiation of the NOF from odontogenic and nonodontogenic cysts and tumors. We report a new case of this interesting entity and review the radiographic, clinical and histologic features of the gnathic NOF reported in the literature. A thorough search of the English language literature returned a total of 19 cases of NOF involving the gnathic bones.
\end{abstract}

Keywords Non-ossifying fibroma - Benign fibrous histiocytoma - Fibrous cortical defect $\cdot$ Mandible

\section{Introduction}

The non-ossifying fibroma (NOF) was first recognized by Sontag and Pyle around 1941 [1]. The following year, Jaffe and Lichtenstein formally identified the lesion and termed it the "non-osteogenic fibroma of bone" [2]. The NOF is

L. M. Bowers $(\bowtie) \cdot$ D. M. Cohen · I. Bhattacharyya ·

J. C. Pettigrew Jr.

Oral and Maxillofacial Diagnostic Sciences,

University of Florida, Gainesville, FL, USA

e-mail: lbowers@dental.ufl.edu

M. F. Stavropoulos

Department of Oral and Maxillofacial Surgery,

University of Florida, Gainesville, FL, USA classified as a tumor-like lesion grouped according to the histologic classification of bone tumors by the World Health Organization (WHO) [3, 4]. A number of synonyms for the NOF have been used which are descriptive and reflect the natural evolution of the lesion. These names include histiocytic fibrous defect, metaphyseal fibrous defect, fibrous cortical defect [5], fibrous xanthoma and histiocytic xanthogranuloma [6].

Currently, the two most frequently used terms to describe these lesions are the "fibrous cortical defect" (FCD) and the "non-ossifying fibroma" (NOF) [7]. The FCD and the NOF are the most common benign lesions of the skeletal system $[1,8]$, arising most frequently in the metaphyseal region of the distal femur, proximal and distal tibia and fibula in children and adolescents [9]. Radiographic studies in the orthopedic literature have shown that $33 \%$ of otherwise normal children have one or more small fibrous cortical defects [1]. While the NOF occurs with relative frequency in the long bones, NOF of the mandible and other areas of the skeleton are rare $[10,11]$. The first use of the term "non-ossifying fibroma" to describe a lesion of the mandible was made in 1979 [12]. We report a case of NOF discovered in the mandibular ramus of a 22-year-old female and review the radiographic, clinical and histologic features of this unusual entity in the jaws.

\section{Case Report}

A 22 year-old female was referred to the University of Florida Oral and Maxillofacial Surgery Department for evaluation of an asymptomatic lesion of the right mandibular ramus. Radiographic examination revealed a welldemarcated, expansile radiolucency with pronounced sclerotic borders. The lesion was unilocular with an 
anterior and superior striated border that was approaching a multilocular stage (Figs. 1a, 2).

The lesion was removed under general anesthesia using a retromandibular incision by thorough curettage and peripheral ostectomy. Intraoperatively, touch preparations and frozen sections were prepared. On the touch prep, blood and macrophagocytic cells were seen while on the frozen section, fibrosis, chronic inflammation and macrophages were noted.

The dimensions of the gross specimen were $1.2 \times 0.8 \times 0.8 \mathrm{~cm}$. The specimen was roughly conical, and was composed of beige and pink soft tissue with a yellow-beige cut surface (Fig. 3). Microscopic examination of the formalin-fixed, paraffin-embedded specimens demonstrated a bone-infiltrating, spindle-celled lesion with a storiform pattern, islands of xanthoma cells and scarce multinucleated giant cells (Figs. 4, 5, 6). The spindle cells showed ovoid nuclei with scant eosinophilic cytoplasm (Fig. 7). Clusters of xanthoma cells were observed throughout the lesion. Perivascular infiltration of small blood vessels by lymphocytes was seen in some areas of the lesion. No areas of necrosis, mitoses or atypical nuclei were noted. No hemosiderin pigment and no evidence of bone production were observed. Based upon the histopathologic appearance and correlation with the radiographic presentation, the diagnosis of NOF (involutionary phase) was achieved.

The patient was evaluated at 1 month, 6 months and 1 year following the surgery. At the 1 year follow-up (the most recent data available), the panoramic radiograph showed on-going bony consolidation in the area of the right mandibular ramus (Fig. 1b). The patient continues to be asymptomatic.

\section{Discussion}

The main entity that is often included in the histologic differential diagnosis of NOF is the FCD. The FCD is a small, lytic, intracortical lesion found in children. It is
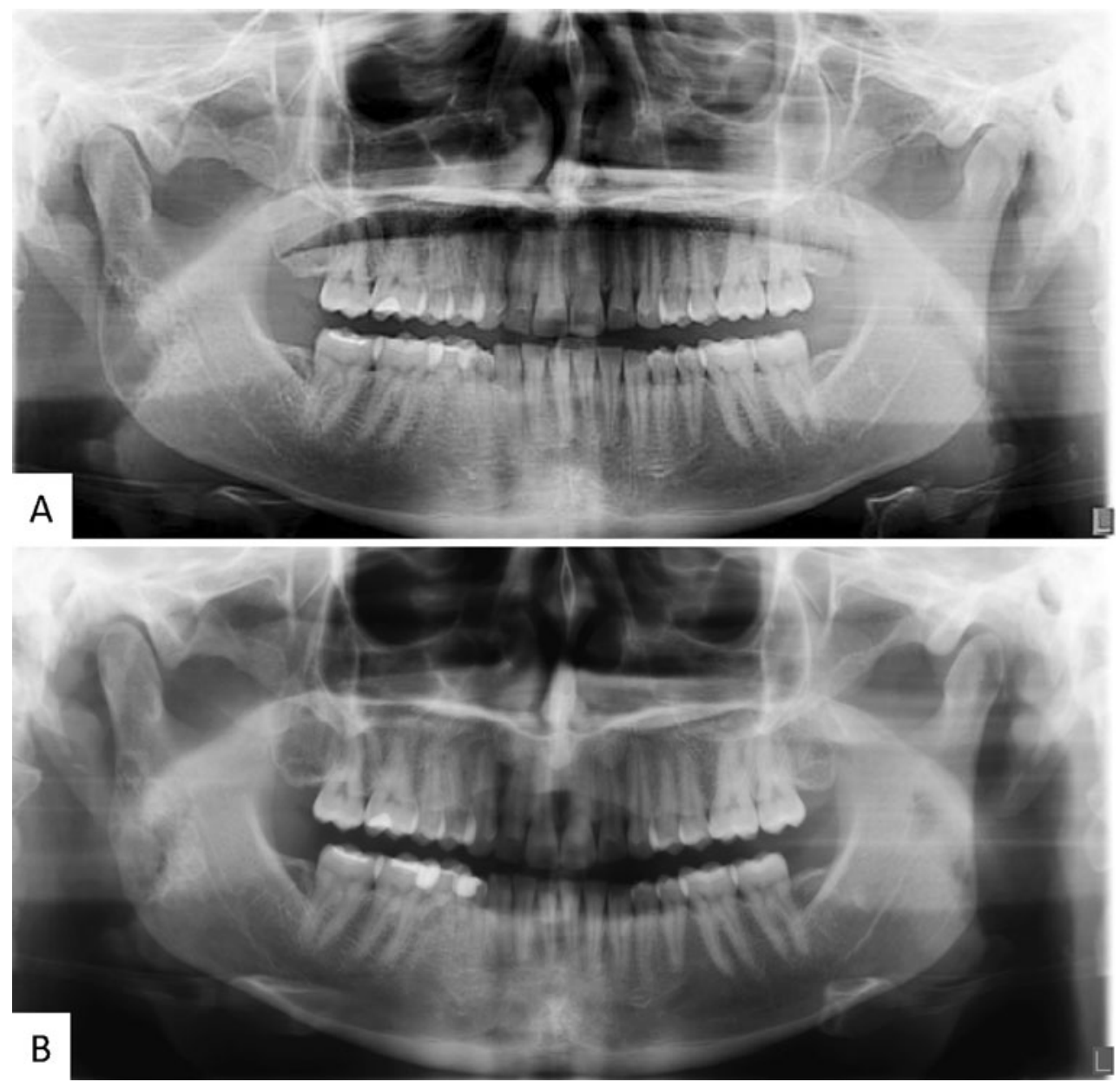

Fig. 1 a Pre-operative radiograph of the non-ossifying fibroma (NOF) of the right mandibular ramus. b One year post-operatively showing ongoing bony consolidation 

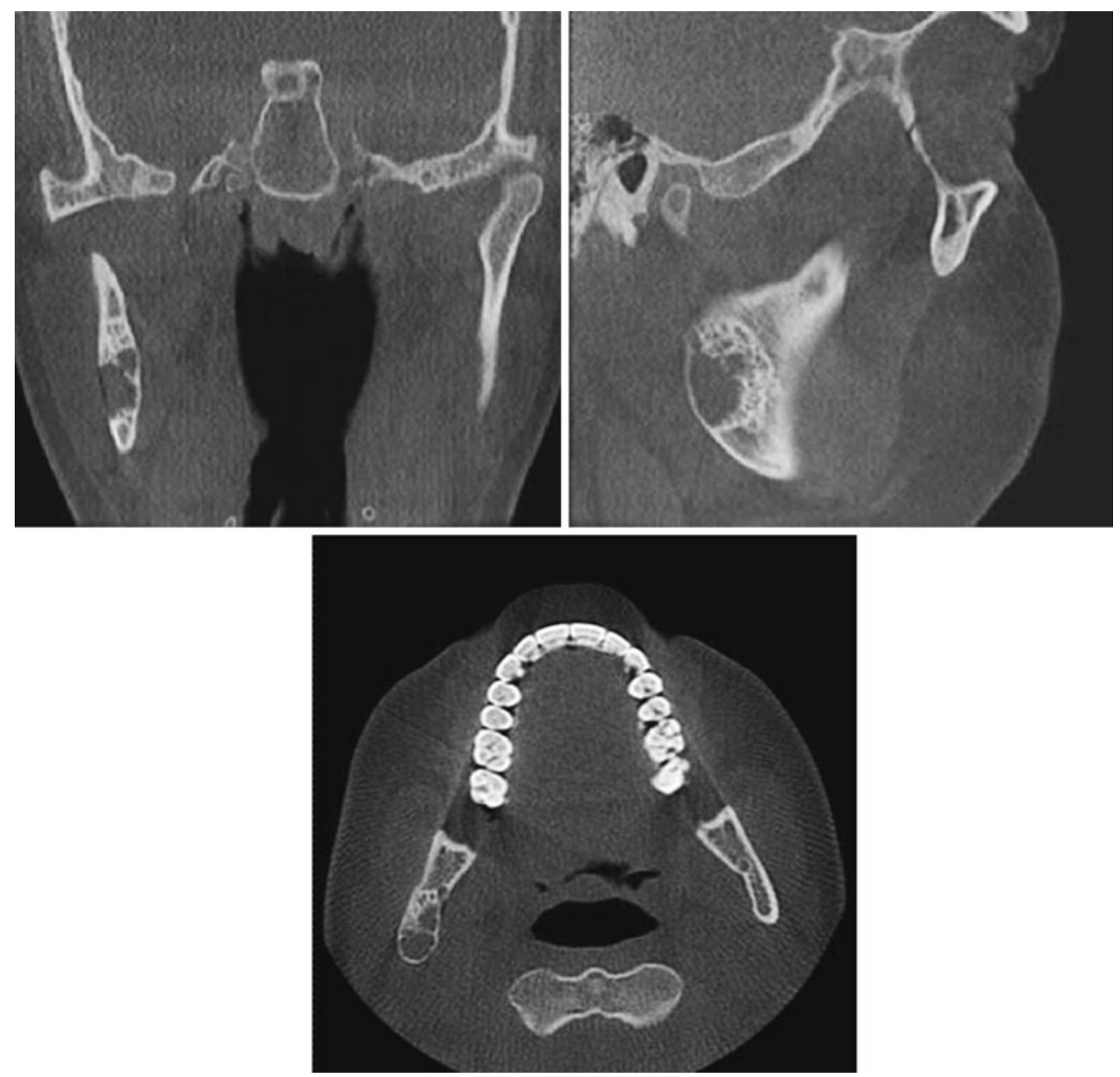

Fig. 2 Pre-operative coronal, sagittal and axial computed tomography views of a non-ossifying fibroma (NOF) of the mandible

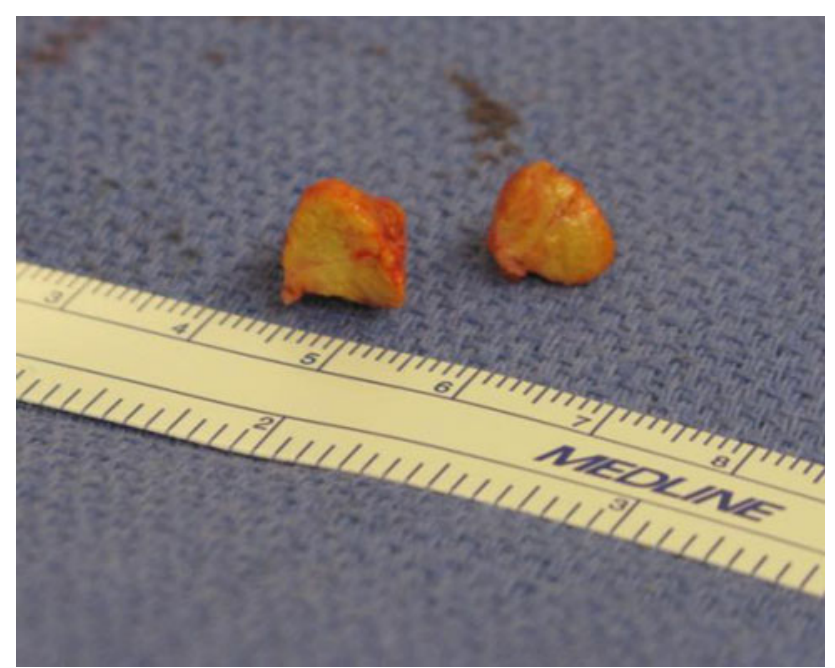

Fig. 3 Gross specimen of the non-ossifying fibroma (NOF)

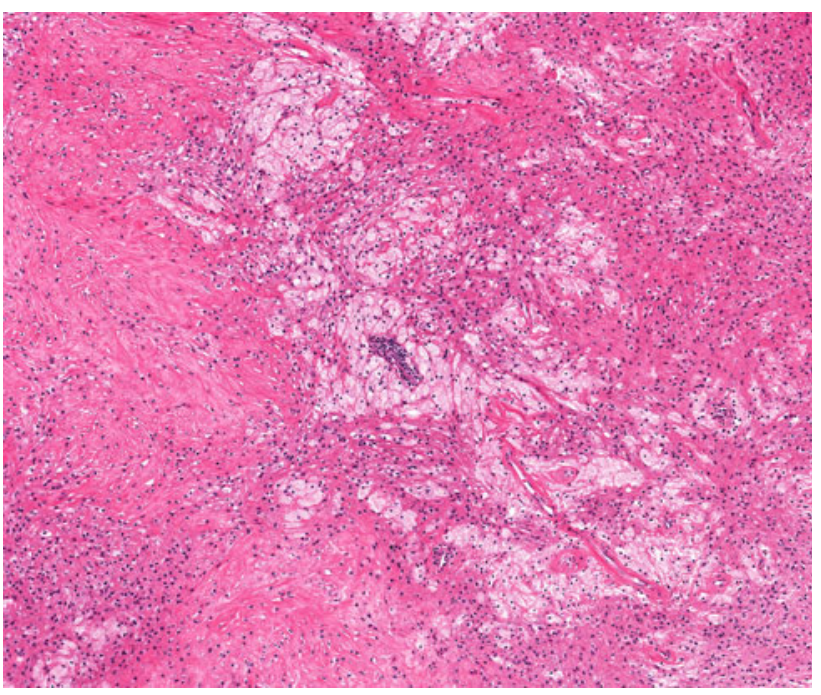

Fig. 4 The non-ossifying fibroma (NOF) showing clusters of xanthoma cells in a fibrous stroma (hematoxylin and eosin, $\times 40$ ) 


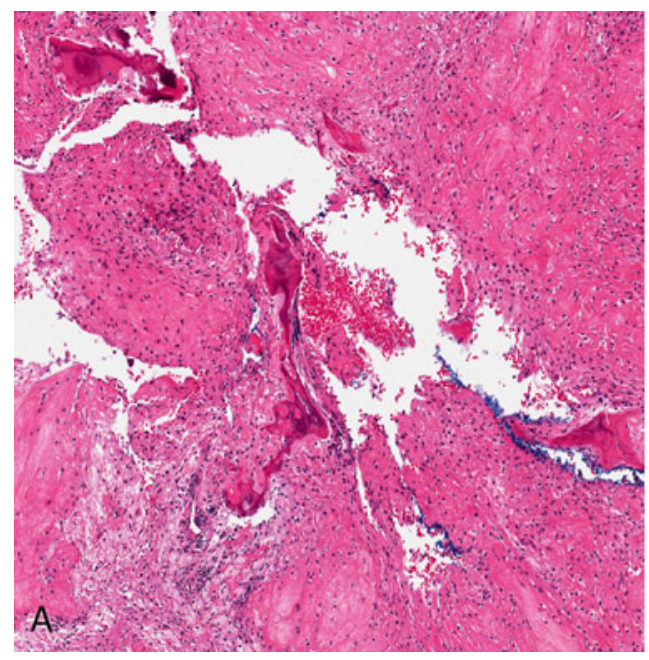

Fig. 5 The non-ossifying fibroma (NOF). a Bony trabeculae, xanthoma cells and fibroblasts (hematoxylin and eosin, $\times 40$ ). b A cluster of xanthoma cells surrounding an endothelium-lined channel

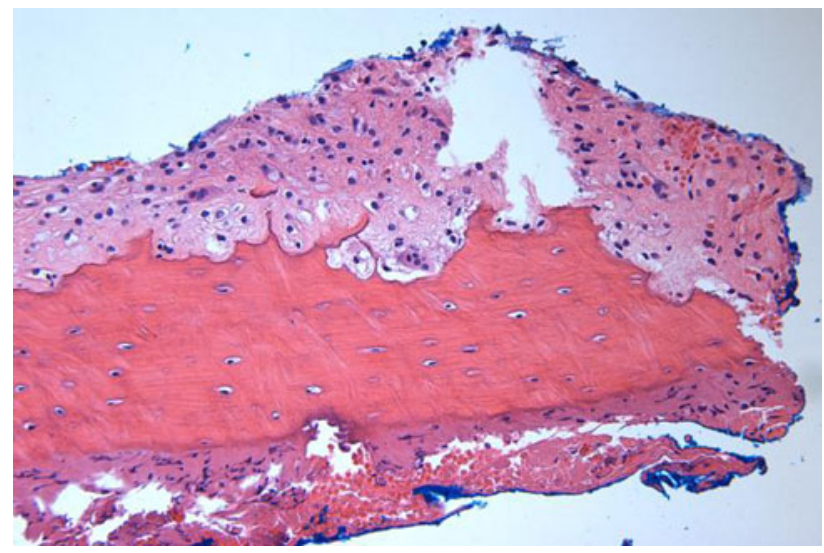

Fig. 6 The non-ossifying fibroma (NOF). Cortical bone with few multinucleated giant cells (hematoxylin and eosin, $\times 200$ )

typically eccentrically located and sharply outlined and represents an osteolytic defect with a thin shell of reactive bone. Generally, because of their small size, FCDs are asymptomatic and are likely to undergo spontaneous regression. Occasionally, the FCD will enlarge, become progressively more separated from the growth plate and extend into the medullary cavity [6]. While the NOF and the FCD refer to the same histopathological process, the NOF is distinguished from the FCD by its larger size $(>3 \mathrm{~cm})$ and extension from the cortex into the medullary cavity $[2,13]$. While the majority of NOFs are asymptomatic, those that are particularly large may cause chronic pain and/or pathologic fracture in the long bones [14, 15].

Diagnosis of NOF in the long bones is based upon the characteristic radiographic and clinical appearance, typically the NOF appears as an asymptomatic multiloculated lesion often identified incidentally during radiographic

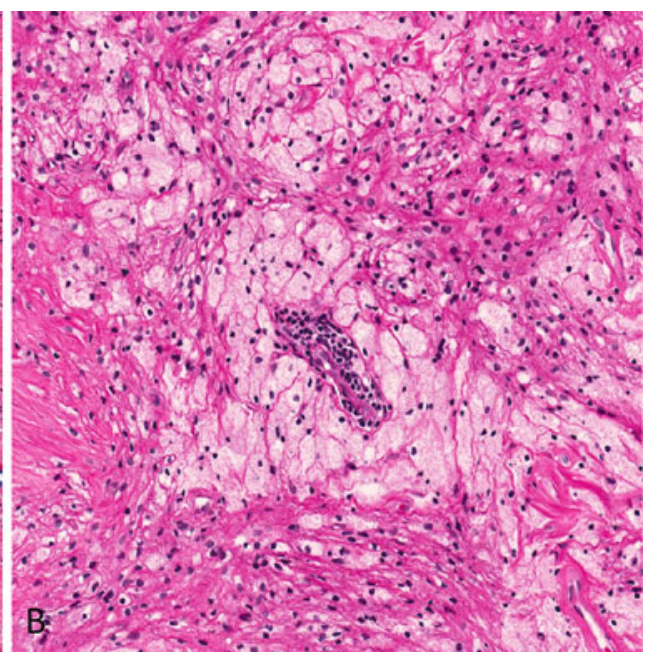

with perivascular lymphocytes and background fibrous stroma (hematoxylin and eosin, $\times 200$ )

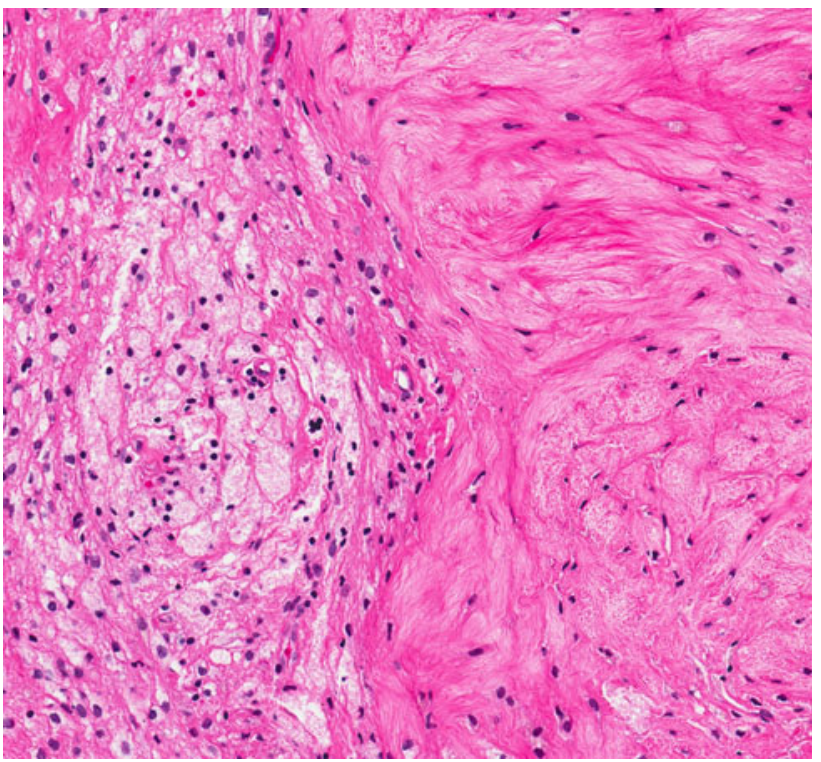

Fig. 7 The non-ossifying fibroma (NOF). Enhanced magnification of xanthoma cells adjacent to spindle cells (hematoxylin and eosin, $\times 200$ )

evaluation indicated for another reason [1, 14, 15]. When arising in a large, tubular bone, the NOF is always eccentric and ovoid and often results in thinning and expansion of the overlying cortex. There is usually no periosteal reaction [16] and no overt violation of the cortex [10]. The lesions are often multilocular in appearance and the inner boundary of the lesion is demarcated by bony sclerosis [7, 13]. While the clinical and radiographic features are pathognomonic for the NOF in the long bones [13], the rarity of this lesion in the mandible makes preoperative diagnosis unlikely. Therefore, correlation of the 
Table 1 Summary of reports of fibrous cortical defect (FCD)/non-ossifying fibroma (NOF) of the mandible

\begin{tabular}{|c|c|c|c|c|c|c|}
\hline Authors & Year published & Age/gender & Site & Size $(\mathrm{cm})$ & Radiological appearance & Treatment \\
\hline Rudy and Scheingold [21] & 1964 & $49 / \mathrm{F}$ & Body/ramus & $\sim 7 \times 4$ & Multilocular & Curettage \\
\hline Quinn et al. [17] & 1970 & $21 / \mathrm{F}$ & Angle & $1 \times 2$ & Unilocular & Curettage \\
\hline Liaw et al. [12] & 1979 & $17 / \mathrm{F}$ & Posterior mandible & NA & Unilocular & Resection \\
\hline Makek [16] & 1980 & $20 / \mathrm{M}$ & Condyle & NA & Multilocular & Resection \\
\hline Ide et al. [18] & 1982 & $37 / \mathrm{F}$ & Body & NA & Multilocular & Curettage \\
\hline Mirra et al. [35] & 1982 & $12 / \mathrm{F}$ & Body & NA & Unilocular & Curettage \\
\hline Park et al. [11] & 1982 & $21 / \mathrm{F}$ & Body & 0.5 & Unilocular & Curettage \\
\hline \multirow[t]{2}{*}{ Elzay et al. [19] } & \multirow[t]{2}{*}{1984} & $11 / \mathrm{F}$ & Ramus & $3 \times 1.5$ & Multilocular & Curettage \\
\hline & & $11 / \mathrm{F}$ & Angle/ramus & $2 \times 1.5$ & Multilocular & Curettage \\
\hline Bessho et al. [22] & 1986 & $28 / \mathrm{M}$ & Body & $2 \times 1$ & Unilocular & Curettage \\
\hline Aldred et al. [20] & 1989 & $18 / \mathrm{F}$ & Condyle & $0.5 \times 0.5$ & Multilocular & Resection \\
\hline Roche et al. [37] & 1993 & $26 / \mathrm{F}$ & Posterior mandible & $2 \times 3$ & Unilocular & Curettage \\
\hline Mizukawa et al. [4] & 1997 & $7 / \mathrm{M}$ & Body & $1.5 \times 1.5$ & Unilocular & Curettage \\
\hline Uçkan et al. [25] & 1999 & $16 / \mathrm{F}$ & Body & NA & Multilocular & Curettage \\
\hline Bailey et al. [24] & 2001 & $6 / F$ & Angle & $1.5 \times 1.5$ & Multilocular & Curettage \\
\hline Hudson et al. [10] & 2003 & $13 / \mathrm{M}$ & Condyle & $1.2 \times 0.5$ & Unilocular & Curettage \\
\hline Chrcanovic et al. [5] & 2010 & $15 / \mathrm{M}$ & Angle & $3 \times 2.5$ & Unilocular & Curettage \\
\hline \multirow[t]{2}{*}{ Abdelsayedet al. [38] } & \multirow[t]{2}{*}{2010} & $14 / \mathrm{F}$ & Ramus & $2 \times 3$ & Multilocular & Curettage \\
\hline & & $27 / M$ & Ramus & $4.5 \times 1.5$ & Multilocular & Curettage \\
\hline Present case & 2011 & $22 / \mathrm{F}$ & Ramus & $1.2 \times 0.8$ & Multilocular & Curettage \\
\hline
\end{tabular}

histopathologic features with the radiographic and clinical presentation is imperative.

There appears to be no consensus in the literature as to the use of the terms non-ossifying fibroma, fibrous cortical defect and metaphyseal fibrous defect when these lesions are found in the gnathic bones. While in the long bones, lesions greater than $3 \mathrm{~cm}$ are given the designation as NOFs, the same cannot be said of gnathic lesions. Some authors have dually designated the lesions as "fibrous cortical defect (non-ossifying fibroma)" or "non-ossifying fibroma (metaphyseal fibrous defect)" [5].

Jaw lesions of the NOF may be asymptomatic $[4,10$, 16-20] or may present with expansion [5, 12, 21, 22]. The radiographic appearance as a well-demarcated multilocular radiolucency with sclerotic borders in the current case and in the majority of other cases reported in the mandible [16, $18,19,21]$ is similar to the typical radiographic appearance in the long bones [7, 20].

The age of presentation of the isolated gnathic NOF appears to differ from that of the long bones in that the gnathic NOF appears at an older average age at diagnosis. The average age at presentation of the 20 examined cases of NOF in the mandible was 19 years and 7 months. In the orthopedic literature, the overall incidence of non-ossifying fibromas in the long bones is $30-40 \%$ of children over the age of 2 with the highest incidence between ages 4 and 8 years [23].

In the reported cases of mandibular NOF, there appears to be a female predilection. In contrast, NOF of the long bones appears more commonly in males [7, 20]. Our review of the reported cases of NOF in the mandible demonstrated that $71 \%$ of them occurred in females (male to female ratio of 1:2.3) [Table 1].

The mandibular NOF appears to have a predilection for the posterior regions such as the condyle, ramus and angle. Fourteen of the 20 cases $(70 \%)$ reported the NOF in these areas. In the long bones, the NOF predominantly occurs in the metaphyses. Interestingly, the ramus and condylar regions of the mandible have been proposed as "imagined" metaphyses given that the posterior aspect of the condyle grows by appositional growth of bone [16].

Bailey et al. [24], in discussing the possible etiology of the NOF, speculated that there may be a relationship between the presence of a greater amount of red marrow in particular sites in the mandible, namely the condyle and angle, and the predilection of the NOF for these sites. The paucity of red marrow in the maxilla may explain the lack of reports of NOF in the maxilla.

While the definitive etiology of the NOF is unclear, it is considered to be a disturbance of growth or dystrophic calcification, rather than a tumor or neoplasm $[10,20]$. The presence of the NOF outside tooth-bearing areas, however, excludes an odontogenic origin [5].

There are reports of NOF in the long bones with clonal rearrangements in chromosomes $1,3,4,11$, and 14 . The presence of clonal chromosomal changes may suggest genetic events associated with tumorigenesis in the 
reported NOFs. Further study is required to determine whether there are consistent karyotypic aberrations associated with the NOF [15]. To date, no studies have reported clonal rearrangements in NOF of the mandible.

Histologically, the NOF consists of spindle-celled fibrous tissue in a storiform pattern with a variable number of multinucleated giant cells, hemosiderin pigment within fibroblasts, and lipid-laden histiocytes (xanthoma cells) [3, 4]. This histologic make-up is reflected in the gross appearance of the lesion: the cut surface of the gross specimen typically appears yellow, due to the lipid content, with a varied degree of brown speckling depending upon the amount of hemosiderin deposition [7, 20]. In addition, occasional lymphocytes and endothelial-lined blood vessels are present $[17,19,20]$. The background stroma is composed of reticulin fibers [13, 23]. Collagen formation is not typically prominent and small foci of osseous metaplasia are rare [7].

Among NOFs, there can be considerable variation in the number of giant cells, histiocytes, or foam cells present as well as the amount of hemosiderin. In our case, there were scant giant cells and no detectable hemosiderin. In other cases of mandibular NOF, giant cells have been reported to be scattered throughout the lesion. [5, 10, 19, 24]. The foam or xanthoma cells are often a distinctive feature of the NOF and are thought to represent secondary, regressive changes rather than neoplasia $[7,16,20,26,27]$. These xanthoma cells are thought to represent a transformation of fibrocytes that may be seen in the later, involution phase of the lesion. Fibrous and xanthomatous forms of NOF may be distinguished histologically, although they may occur synchronously [16].

Treatment of the FCD/NOF of the long bones, particularly in asymptomatic cases, is observation. These lesions are typically self-limiting and spontaneous resolution at skeletal maturity is usually seen, especially in the smaller lesions of the FCD [2, 24]. This spontaneous regression, usually starting at the end of adolescence, has been observed to occur over periods of 29-52 months [1]. Most NOFs also resolve spontaneously but usually take longer than FCDs owing to their larger size [28]. The regressive phase is observed radiographically as a "fading out" of the lesion: trabecular bone growth appears to occur from the periphery inward until the bone is reconstituted to a normal state [28, 29].

The clinical behavior of cases of NOF in the mandible appears to be that of a benign lesion with no reports of recurrence; similar to that seen in the long bones. The rarity of reports in the literature of the NOF in the adult indicates that most of these lesions also undergo spontaneous regression with time [13].

The apparent developmental nature of the NOF lends itself to conservative treatment. Most mandibular lesions are small and asymptomatic. All reported cases of NOF of the mandible have been successfully treated by curettage or resection with no reports of recurrence. Radiotherapy is not indicated [5, 16]. One case in the mandibular condyle reported by Hudson et al., was identified intraoperatively by frozen section (and later confirmed by routine microscopy) and was treated using endoscopic visualization and aggressive curettage without disruption of the condylar head followed by intracapsular matrix augmentation using freeze-dried collagen. Eighteen months post-operatively, bony consolidation and resolution of the lytic region of the condyle were observed [10]. While malignant transformation to an aggressive fibrosarcoma has been reported in one case of NOF occurring in the tibia [30], the postoperative course is usually uneventful [4].

\section{Differential Diagnoses}

The clinical and radiographic presentation of the nonossifying fibroma in the mandible may lend itself to multiple differential diagnoses but the lack of cortical violation, asymptomatology and distinct histologic appearance are characteristic of this lesion [10].

Lesions with a similar clinical and radiographic presentation may include the ameloblastoma and odontogenic myxoma. The ameloblastoma may also present radiographically as a multicystic radiolucency, however, the septae seen in the classic "soap bubble" appearance tend to be coarser and the individual locules are typically larger than those seen in the NOF. The odontogenic myxoma can also have a multilocular appearance but the septae of the residual bone are often linear and arranged at right angles to one another [31]. Aneurysmal bone cysts and central giant cell granulomas (CGCG) may also present similarly but are distinguishable histologically.

Neurofibromatosis radiographically can mimic NOF if it presents with intramedullary cyst-like rarefaction or with cortical erosions without cortical breach. However, clinical features of neurofibromatosis often include skin nodules, palpable neurofibromas and a possible positive family history. In addition, histologic differences allow for distinguishing the two. [13].

Histologically, when a prominent giant cell distribution is seen, the differential diagnoses may include a benign fibrous histiocytoma (BFH), a malignant fibrous histiocytoma (MFH) [undifferentiated pleomorphic sarcoma], a central giant cell granuloma (CGCG), and a brown tumor of hyperparathyroidism. The presence of other clinical, radiographic or histologic features allow for distinction.

The BFH of the bone is histologically indistinguishable from NOF and radiographically, both may show welldefined, sclerotic margins [6,32]. The BFH, however, occurs with greater frequency in older patients $(60 \%$ are older than 
20 years of age), is often symptomatic in the absence of complicating fractures and has the potential to recur [33]. Because of its tendency to recur after curettage, it is necessary to distinguish the BFH from the NOF [34]. This particular case was designated as a non-ossifying fibroma due to the patient's young age and asymptomatology.

The MFH typically appears in patients between the ages of 50 and 70 years of age and will usually present as a painless, enlarging mass of several months' duration. Imaging of the MFH will show a lytic process with destruction of the cortex. While there are a variety of histologic appearances, in general, all will show significant nuclear pleomorphism and mitotic activity.

The CGCG may be seen in patients from infancy to old age but is most common in those less than 30 years of age. It is typically asymptomatic and appears as a unilocular or multilocular radiolucency that often appears to straddle the midline of the mandible. The multinucleated giant cells in the CGCG appear to be scant to abundant either in discrete aggregates or diffusely distributed throughout the lesion in a background of vascular granulation tissue. Areas of erythrocyte extravasation and hemosiderin deposition are also seen. The appearance of the brown tumor of hyperparathyroidism is histopathologically identical to that of the CGCG, but may be differentiated based upon history and laboratory and/or clinical findings. In addition, the CGCG and brown tumor of hyperparathyroidism can usually be distinguished by the number of giant cells: rarely are they present in the same numbers in the NOF [20].

\section{Association with Jaffe-Campanacci Syndrome}

Patients with Jaffe-Campanacci syndrome (disseminated multiple NOF in association with café-au-lait spots, mental retardation, hypogonadism, and congenital ocular or cardiac anomalies) often have mandibular lesions of NOF [5, $24,35]$. In a review by Blau, of the 8 patients with multiple NOFs and cafe-au-lait spots, five had a mandibular lesion, four were mentally retarded, one had precocious puberty, and two had a congenital ocular anomaly [13].

Campanacci et al. [36] hypothesized that this syndrome may represent an atypical presentation of neurofibromatosis. The lesions of NOF in the long bones in this syndrome are reported to be more aggressive with a higher rate of associated pathologic fracture and resolution of the lesions at the completion of skeletal maturity [24].

In conclusion, NOF of the mandible may present as a multilocular radiolucency. While the radiographic and clinical appearance of the NOF/FDC of the long bones is considered pathognomonic, these lesions are rare in the gnathic bones and may mimic other odontogenic or nonodontogenic cysts and tumors. While the histopathologic components of the NOF are variable, they are often quite characteristic and clinical and radiographic correlation is required to reach a definitive diagnosis.

\section{References}

1. Sontag LW, Pyle DI. The appearance and nature of cyst-like areas in distal femoral metaphyses of children. Am J Roentgenol Radiat Ther. 1941;46:185-8.

2. Jaffe HL, Lichtenstein L. Non-osteogenic fibroma of bone. Am J Pathol. 1942;18:205-20.

3. Schajowicz F, Ackerman LV, Sissons HA, et al. International histological classification of tumors (histological typing of bone tumors). Geneva: World Health Organization; 1993.

4. Mizukawa N, Nishijima Y, Nishijima K. Metaphyseal fibrous defect (non-ossifying fibroma) in the mandible. A case report. Int J Oral Maxillofac Surg. 1997;26:129-30.

5. Chrcanovic B, Albanese AL, Freire-Maia B, et al. Non-ossifying fibroma (metaphyseal fibrous defect) of the mandible. Oral Maxillofac Surg. 2011;4:233-7.

6. Fletcher CDM, Unni KK, Mertens F. World Health Organization: classification of tumours. Pathology and genetics of tumours of soft tissue and bone. Lyon: IARC Press; 2002.

7. Dahlin DC. Fibroma (nonosteogenic fibroma of bone, metaphyseal fibrous defect), myxoma, cortical desmoid, fibromatosis, and "Xanthoma". In: Thomas CC, editor. Bone tumors. general aspects and data on 6,221 cases, 3rd ed. Springfield, IL: Charles C Thomas; 1978. p. 122-36.

8. Betsy M, Kupersmith LM, Springfield DS. Metaphyseal fibrous defects. J Am Acad Orthop Surg. 2004;12:89-95.

9. Glockenberg A, Sobel E, Noel JF. Nonossifying fibroma. Four cases and review of the literature. J Am Podiatr Med Assoc. 1997;87(2):66-9.

10. Hudson JW, Livesay KW, McCoy JM. Condylar lesion. J Oral Maxillofac Surg. 2003;61:824-6.

11. Park JK, Levy BA, Hanley JB. Non-ossifying fibroma of the mandible: report of a case. J Baltim Coll Dent Surg. 1982;35:1-5.

12. Liaw WJ, So TK, Yao YT. Non-ossifying fibroma of mandible. A case report. J Formos Med Assoc. 1979;78:795-802.

13. Blau RA, Zwick DL, Westphal RA. Multiple non-ossifying fibromas. A case report. J Bone Joint Surg Am. 1988;70:299-304.

14. Shaffer LG, Tommerup N, editors. ISCN 2005: an international system for human cytogenetic nomenclature. Basel: S. Karger; 2005.

15. Brassesco MS, Valera ET, Engel EE, et al. Clonal complex chromosome aberration in non-ossifying fibroma. Pediatr Blood Cancer. 2010;54:764-7.

16. Makek M. Non-ossifying fibroma of the mandible. A common lesion with unusual location. Arch Orthop Trauma Surg. 1980;96:225-7.

17. Quinn JH, Graves LR, Leonard GI. Unusual histiocytic lesion of the mandible: report of a case. J Oral Surg. 1970;28:528-30.

18. Ide F, Kusuhara S, Onuma $\mathrm{H}$, et al. Xanthic variant of the nonossifying fibroma (so called xanthofibroma) of the mandible: an ultrastructural study. Acta Pathol Jpn. 1982;32:135-42.

19. Elzay RP, Mills S, Kay S. Fibrous defect (non-ossifying fibroma) of the mandible. Oral Surg Oral Med Oral Pathol. 1984;58:402-7.

20. Aldred MJ, Breckon JJW, Holland CS. Non-osteogenic fibroma of the mandibular condyle. $\mathrm{Br} \mathrm{J}$ Oral Maxillofac Surg. 1989;27:412-6.

21. Rudy HN, Scheingold SS. Solitary xanthogranuloma of the mandible. Report of a case. Oral Surg Oral Med Oral Pathol. 1964;18:262-71. 
22. Bessho K, Murakami K, Nishida M, et al. Non-ossifying fibroma of the mandible: case report and review of literature. Jpn J Oral Maxillofac Surg. 1986;32:291-6.

23. Huvos AG. Nonossifying Fibroma. In: Bone tumors: diagnosis, treatment, and prognosis. Philadelphia, PA: W. B. Saunders; 1979. p. 297-306.

24. Bailey JS, Nikitakis NG, Lopes M, et al. Non-ossifying fibroma of the mandible in a 6-year-old girl: a case report and review of the literature. J Oral Maxillofac Surg. 2001;59:815-8.

25. Uçkan S, Gürol M, Mutlu N, et al. Non-ossifying fibroma of the mandible: report of a case. Br J Oral Maxillofac Surg. 1999;37: $152-4$.

26. Spjut HJ, Dorfman HD, Fechner RE, Ackerman LV. Tumors of bone and cartilage. In: Atlas of tumor pathology, second series, fascicle 5. Washington: Armed Forces Institute of Pathology; 1971. p. 249-50.

27. Harsanyi BB, Larsson A. Xanthomatous lesions of the mandible: osseous expression of non- $\mathrm{X}$ histiocytosis and benign fibrous histiocytoma. Oral Surg Oral Med Oral Pathol. 1988;65(5): 551-66.

28. Mirra JM. Fibrohistiocytic tumors intramedullary origin. In: Mirra JM, editor. Bone tumors: clinical, radiologic, and pathologic correlation. Philadelphia: Lea \& Febiger; 1989. p. 692-731.

29. Hatcher $\mathrm{CH}$. The pathogenesis of localized fibrous lesions in the metaphyses of long bones. Ann Surg. 1945;122:1016.
30. Bhagwandeen SB. Malignant transformation of a non-osteogenic fibroma of bone. J Pathol. 1966;92:562-4.

31. Heo MS, Cho HJ, Kwon KJ, et al. Benign fibrous histiocytoma in the mandible. Oral Surg Oral Med Oral Pathol Oral Radiol Endod. 2004;97:276-80.

32. Neville B, Damm D, Allen C, Bouquot J. Oral \& maxillofacial pathology. 3rd ed. Philadelphia: Saunders; 2009. p. 729-31.

33. Roche WC, Krishnan V, McDaniel RK. Fibrous defect of the mandible: a case report and literature review. J Oral Maxillofac Surg. 1993;51:809-11.

34. Fechner RE, Mills SE. Tumors of the bone and joints. In: Rosai J, Sobin LH, editors. Atlas of tumor pathology, 3rd series, 8th fascicle. Washington: AFIP; 1993. p. 129-44.

35. Hamada T, Ito H, Araki Y, et al. Benign fibrous histiocytoma of the femur: review of three cases. Skeletal Radiol. 1996;25:25-9.

36. Campanacci $M$, Laus M, Boriani S. Multiple non-ossifying fibromata with extraskeletal anomalies: a new syndrome? J Bone Joint Surg Br. 1983;65:627-32.

37. Mirra JM, Gold RH, Rand F. Disseminated non-ossifying fibromas in association with café-au-lait spots (Jaffe-Campanacci syndrome). Clin Orthop Relat Res. 1982;168:192-205.

38. Abdelsayed RA, Sharma S, Ferguson H. Fibrous cortical defect (nonossifying fibroma) of the mandibular ramus: report of 2 cases. Oral Surg Oral Med Oral Pathol Oral Radiol Endod. 2010;110:504-8. 